\title{
D’Arcy W. Thompson's Cartesian transformations: a critical evaluation
}

\author{
Gerhard Scholtz $^{1,3} \cdot$ David Knötel ${ }^{2,3} \cdot$ Daniel Baum ${ }^{2,3}$
}

Received: 21 March 2020 / Revised: 11 June 2020 / Accepted: 15 June 2020 / Published online: 27 June 2020

(c) The Author(s) 2020

\begin{abstract}
The images of D'Arcy Wentworth Thompson's book “On Growth and Form" got an iconic status and became influential for biometrics and other mathematical approaches to organismic form. In particular, this is true for those of the chapter on the theory of transformation, which even has an impact on art and humanities. Based on his approach, Thompson formulated far-reaching conclusions with a partly anti-Darwinian stance. Here, we use the example of Thompson's transformation of crab carapaces to test to what degree the transformation of grids, landmarks, and shapes result in congruent images. For comparison, we applied the same series of tests to digitized carapaces of real crabs. Both approaches show similar results. Only the simple transformations show a reasonable form of congruence. In particular, the transformations to majoid spider crabs reveal a complicated transformation of grids with partly crossing lines. By contrast, the carapace of the lithodid species is relatively easily created despite the fact that it is no brachyuran, but evolved a spider crab-like shape convergently from a hermit crab ancestor.
\end{abstract}

Keywords Biometrics · B-spline · Crabs · Crustaceans · Decapoda · Form · Humanities · Icons · Landmarks · Transformation

\section{Introduction}

About a century ago, D'Arcy Wentworth Thompson published his seminal book "On Growth and Form" (Thompson 1917). With this publication, Thompson initiated a mathematical and physical approach to the investigation of organismic form and its change during ontogeny and evolution.

The combination of elegant prose, mathematics, and clear illustrations made "On Growth and Form" a success which still has a great impact on various form-related disciplines (Arthur 2006; Ball 2013; Fürst von Lieven 2017; Lecuit and Mahadevan 2017; Saunders and Ingham 2017). In addition to biological morphology (e.g., Riedl 1975; Zelditch et al. 2004; MacLeod 2008; Abzhanov 2017), this is true for fields

Gerhard Scholtz

gerhard.scholtz@rz.hu-berlin.de

1 Humboldt-Universität zu Berlin, Institut für Biologie, Vergleichende Zoologie, Philippstr. 13, 10115 Berlin, Germany

2 Department of Visual Data Analysis, Zuse Institute Berlin, Takustr. 7, 14195 Berlin, Germany

3 Cluster of Excellence: Image Knowledge Gestaltung, Sophienstr. 22a, 10178 Berlin, Germany such as mathematics, materials science, geography, architecture, and art (e.g., Bookstein 1977; Beesley and Bonnemaison 2008; Fratzl and Weiner 2010; Werritty 2010; Dunlop et al. 2011; Marsland et al. 2012; Höfler 2013; Jarron 2015) sometimes including somewhat esoteric aspects (Doczi 1981). In particular, the famous final chapter "On the theory of transformations, or the comparison of related forms", in which Thompson applied Cartesian transformations to biological shapes, has been frequently discussed and cited in the biological literature and beyond. This chapter is a slightly modified version of an earlier publication (Thompson 1915). The illustrations of this chapter became widespread and reached iconic status. This is reflected in numerous recent studies applying Thompson's characteristic grid graphs to visualize biological shape transformations and in the thriving discipline of geometric morphometrics used for functional, taxonomic, phylogenetic, and evolutionary inferences (e.g., Zelditch et al. 2004; Hiller et al. 2006; Sanfelice and de Freitas 2007; Oxnard and O'Higgins 2009; Abzhanov 2017; Ospina-Garcés et al. 2018). Likewise, modern approaches to the morphing of natural and artificial structures and forms like, e.g., Hollywood movies' special effects, are not conceivable without Thompson's work, although these use more sophisticated mathematical methods. Examples for this can 
be found in biology, architecture, and psychology (e.g., Lynn 2017; Knötel et al. 2018; Reindl et al. 2018).

Thompson's theory of transformation polarized biologists and philosophers of biology. On the one hand, his approach has been seen as important for the understanding of external and internal shaping forces, the view of correlations, connections, coherence or interdependency of organismic structures and of organisms as (genetically) integrated entities, and a mathematical approach to questions of form (Gould 1971; Gould and Lewontin 1979; Richter and Wirkner 2013; Abzhanov 2017). On the other hand, there are those who take a critical stance toward Thompson's approach. A major criticism is that evolutionary transformation is not a case of direct change of adult animal forms. As Arthur (2006) wrote, “....it must have been obvious to D'Arcy Thompson as it is to biologists today that there is no way evolution can turn one sort of adult form into another except by modifying the course of development." Furthermore, Thompson's approach has been criticized by philosophers of biology and biologists as pre-Darwinian idealistic, essentialistic, typological, structuralistic, and largely ahistorical (Asma 1996: $151 \mathrm{ff}$;; Mahner and Bunge 1997: 295; Breidbach 2008: 18; Scholtz 2013: 39ff.; see Ruse 2013).

In the first edition of "On Growth and Form", Thompson (1917: 724) described his approach as follows: "Let us inscribe in a system of Cartesian co-ordinates the outline of an organism, however complicated, or a part thereof: such as a fish, a crab, or a mammalian skull. We may now treat this complicated figure, in general terms, as a function of $x, y$. If we submit our rectangular system to 'deformation' on simple and recognized lines, altering, for instance, the direction of the axes, the ratio of $x / y$, or substituting for $x$ and $y$ some more complicated expressions, then we shall obtain a new system of co-ordinates, whose deformation from the original type the inscribed figure will precisely follow." Hence, seemingly very different shapes appear as a result of relatively simple geometric transformations, e.g., shearing or conformal mappings (i.e., angle preserving transformations), which are called Cartesian transformations throughout this paper. Furthermore, this view implies that the shape transformation between different species involves the whole structure and does not relate only to individual parts that are changed autonomously from the remaining structures. In other words, biological transformation is a change of integrated structural wholes and follows simple mathematical models.

Thompson understood his results as evidence against a Darwinian view of many minute and independent adaptive changes that, in the end, lead to a different structure. Instead, he stressed that the alteration of form follows mathematical rules or laws that are inherent to the form and which allow for changes within a certain framework of shape-related forms but not beyond a certain threshold (Thompson 1917,
1942). This stance is already expressed in the final section of the penultimate chapter "On form and mechanical efficiency" named "The Problem of Phylogeny" in the 1917 edition of Thompson's book (1917: 715 ff.). This section leads to the central question of transformation and sets the frame for the view that form change over time can only be understood if organismic forms are conceptualized as integrated wholes. In the second edition of 1942, Thompson added a "Conclusion" section to the chapter on transformation, in which he even more strongly rejects Darwinian principles of evolution. This is reflected in sentences like, “...; for eighty years' study of Darwinian evolution has not taught us how birds descended from reptiles, mammals from earlier quadrupeds, quadrupeds from fishes, nor vertebrates from the invertebrate stock." (Thompson 1942: 1093). In addition, he stated, "...the breach between vertebrate and invertebrate, worm and coelenterate, coelenterate and protozoon, (...), is so wide that we cannot see across the intervening gap at all." (Thompson 1942: 1093). Based on this perspective, Thompson concluded that there is a general "principle of discontinuity" that is "...inherent in all our classifications, whether mathematical, physical or biological..." (Thompson 1942: 1094).

These are far-reaching conclusions, and it has to be asked whether they are justified based on Thompson's data and images. Thompson was not very explicit about the method that he used to create his images (see also Bookstein 1977: 181). For instance, it is entirely unclear what landmarks he used to fit the organismic form into a grid and how he transformed the grids (Thompson 1917: 724 f.). Furthermore, Thompson postulated, "Again, it is essential that our structure vary (sic!) in its entirety, or at least that 'independent variants' should be relatively few." (Thompson 1917: 726). However, he never made clear how many "independent variants" are allowed for the application of his method and how to recognize these beforehand. Hence, one needs to ask the question: how reliable are Thompson's images dealing with Cartesian transformations? Already Bookstein (1977: 181) discussed some inconsistencies in the images of the quite famous transformation of the porcupine-fish Diodon to the sunfish Mola (Thompson 1917: 751, Figs. 381,382) relating to symmetries and proportions of some details. However, a systematic and detailed investigation of the "correctness" of Thompson's images and inferences has so far not been carried out.

In his essay on the "Theory of transformation", Arthur (2006) stressed that "all the tools are now in place" to test Thompson's ideas. In particular, he referred to computers and computer graphics. Following his suggestion, we here use the example of crab carapaces (Fig. 1, row 1) to evaluate the relationship between grids and shape alteration. We pursue a two-step approach. First, we take Thompson's original drawings, and transform them with modern image 
a
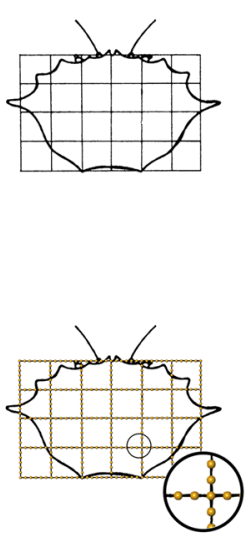
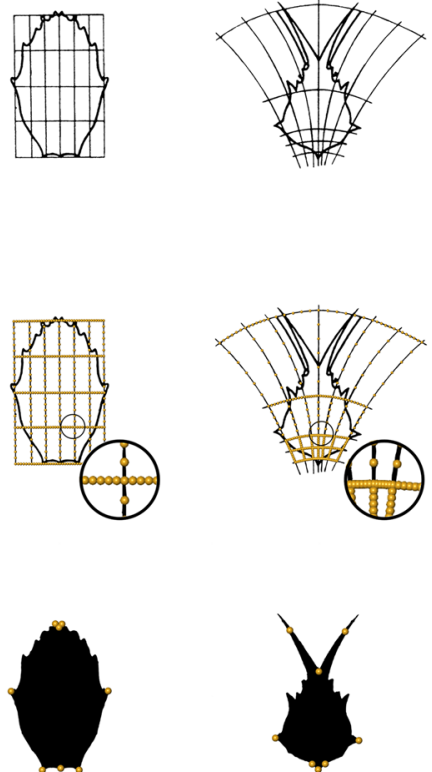

d
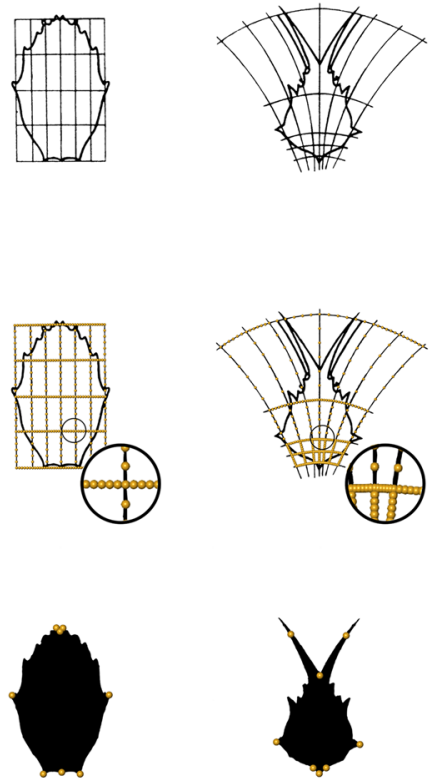
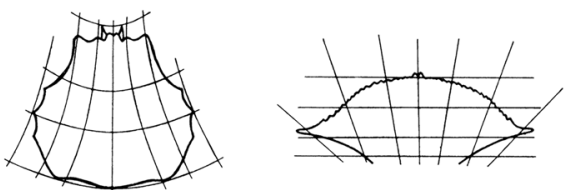

e

$\mathrm{f}$
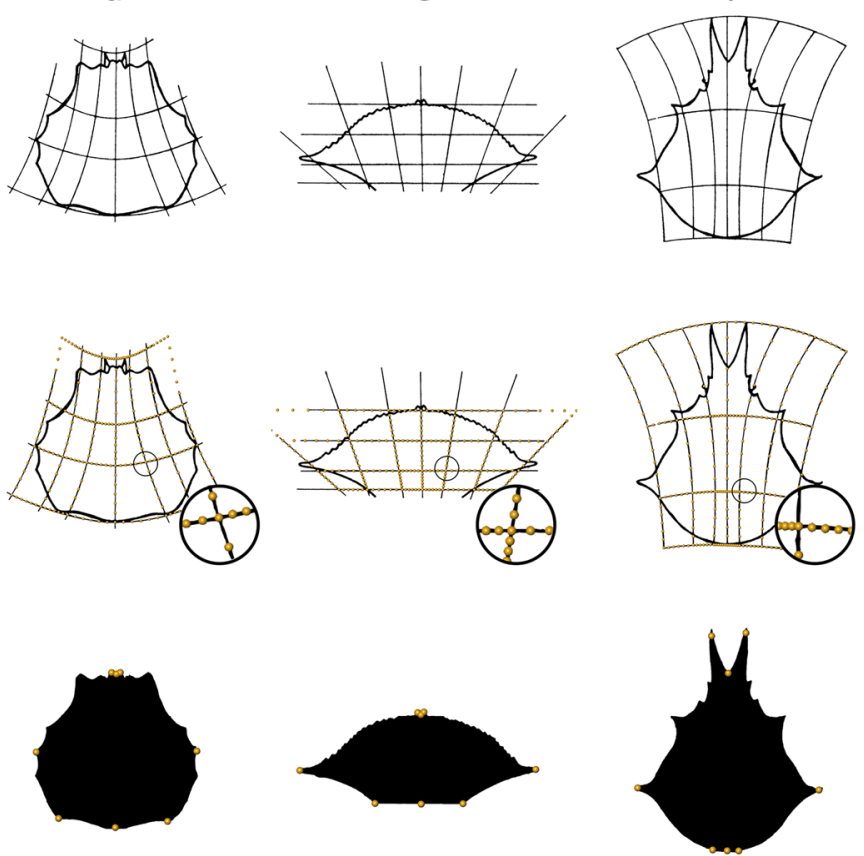

Fig. 1 Images used for our analysis of Thompson's (1917) own illustrations. The current genus names are written in brackets. From left to right: a Geryon, b Corystes, c Scyramathia (Rochinia), d Paralomis, e Lupa (Portunus), and $\mathbf{f}$ Chorinus. First row: original transfor-

mations of crab carapaces by D'Arcy Thompson (Thompson 1917, Fig. 369). Second row: sampling of Thompson's grids with landmarks. Third row: black-and-white silhouettes with eight manually placed landmarks (yellow dots)

registration software. Additionally, we use 3D scans of real crab species to apply several methods of shape transformation. At the same time, we use these analyses to test whether crab carapaces can be interpreted as integrated entities that are composed of correlated structures.

\section{Materials and methods}

To test the exactness of Thompson's own illustrations and the respective transformations, we digitized the line drawings of six crab carapaces from Thompson (1917) (Fig. 1, row 1). The images were resampled to a size of $1600 \times 1600$ pixels. We sampled Thompson's grids with regularly distributed landmarks and generated black-and-white silhouette images of the carapaces (Fig. 1, rows 2 and 3). The transformations according to Thompson's images were computed in two ways: first by superimposing the grids of two carapaces and second by superimposing the silhouette images.

Furthermore, to test Thompson's claim of Cartesian transformation with the shapes of real animals, we digitized a number of carapaces of crab species. For this purpose, we used a Skiron Surface Laser Scanner (Kreon Technologies, Limoges, France) with a resolution of $50 \mu \mathrm{m}$ mounted on a MicroScribe M model (Revware, Raleigh, North Carolina, USA) in combination with the software Scantools

3D (version 2.0.8, Kreon Technologies, Limoges, France; HADCAM Ltd., Munich, Germany). For his transformation of crab carapaces, Thompson (1917) chose species of five genera of the Brachyura or true crabs. Three of the major brachyuran taxa are covered by his approach; the reference genus Geryon and the swimming crab Portunus belong to the Portunoidea, the helmet crab Corystes is a representative of the Corystoidea, and the spider crabs Rochinia and Chorinus are genera of the Majoidea ( $\mathrm{Ng}$ et al. 2008) (Table 1). Interestingly, the sixth carapace of Thompson's transformation series, Paralomis is not a genus of the Brachyura but of the Anomala, a morphologically greatly diverse taxon comprising hermit crabs, squat lobsters, and mole crabs among others (Scholtz and Richter 1995) (Table 1). Thompson (1917) merely mentioned the genus names in his publication but not the species. Hence, in obvious cases, we chose the species of which we think that Thompson might have used and, in other cases, we took species with most similar shapes and proportions (Table 1, Fig. 2).

All digitized 3D images of the carapaces were horizontally oriented and projected onto a plane to obtain a blackand-white silhouette representation (Fig. 2). We specified eight landmarks on each carapace. These were based on carapace lines as defined by McLaughlin (1980) and selected as representing points in homologous positions of the various carapaces and included the mirror axis, the margin of the 
Table 1 Carapaces analyzed with respect to transformation

\begin{tabular}{llll}
\hline & $\begin{array}{l}\text { List of genus names of Thompson's draw- } \\
\text { ings (current names in brackets) }\end{array}$ & Species digitized to match Thompson's specimens & Higher taxon \\
\hline$a$ & Geryon & Geryon trispinosus (Herbst, 1803) & Brachyura: Portunoidea \\
$b$ & Corystes & Corystes cassivelaunus (Pennant, 1777) & Brachyura: Corystoidea \\
$c$ & Scyramathia (Rochinia) & Pisa tetraodon (Pennant, 1777) & Brachyura: Majoidea \\
$d$ & Paralomis & Lithodes maja (Linnaeus, 1758) & Anomala: Lithodoidea \\
$e$ & Lupa (Portunus) & Portunus pelagicus (Linnaeus, 1758) & Brachyura: Portunoidea \\
$f$ & Chorinus & Leptomithrax sp. (Miers, 1876) & Brachyura: Majoidea \\
\hline
\end{tabular}
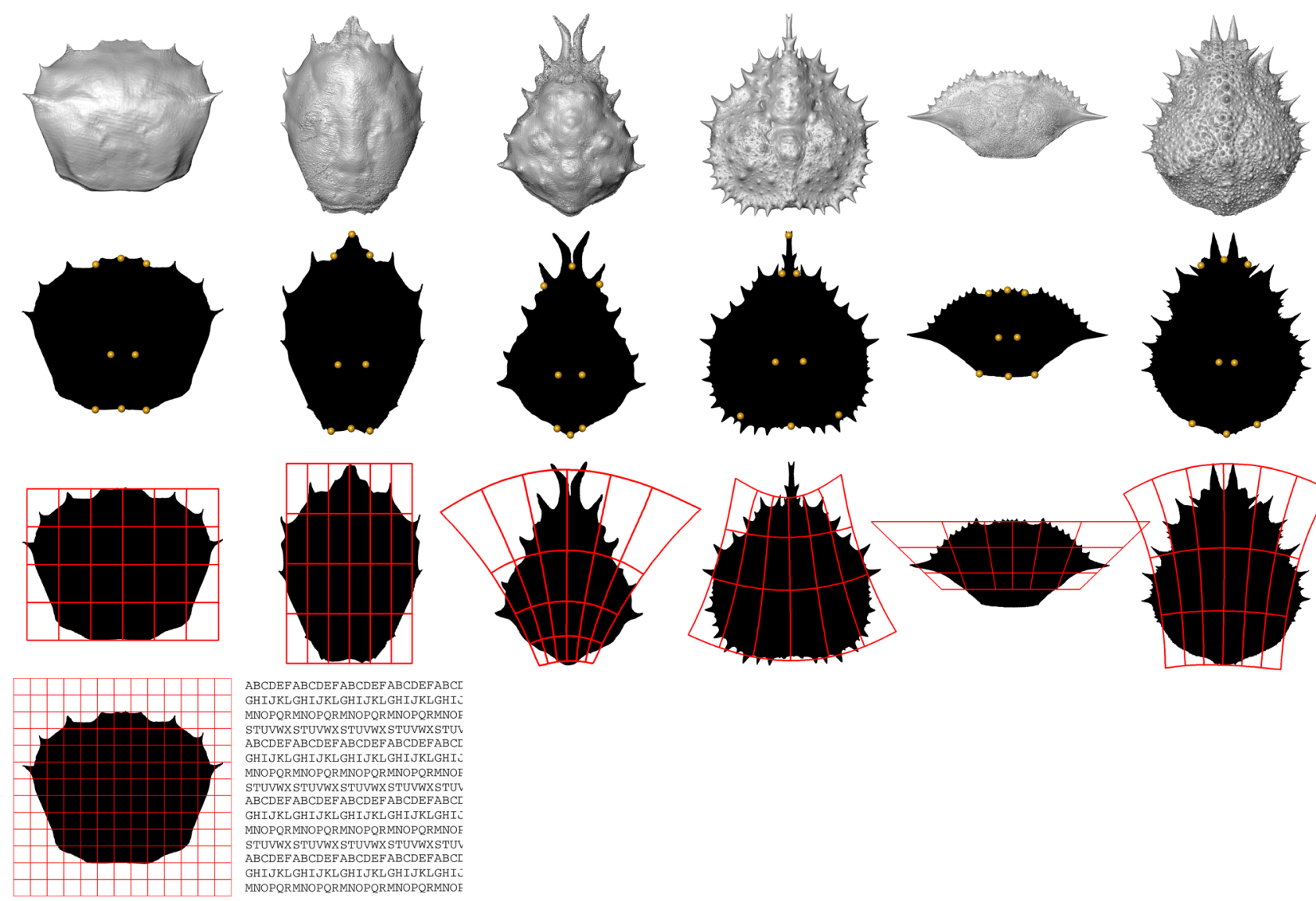

ABCDEFABCDEFABCDEFABCDEFABCL GHIJKLGHIJKLGHIJKLGHIJKLGHI: STUYWXSTUVWXSTUYWWXSTUYYWXSTUT ABCDEFABCDEFABCDEFABCDEFABCI GHIJKLGHIJKLGHIJKLGHIJKLGHI MNOPQRMNOPQRMNOPQRMNOPQRMNOI STUVWXSTUVWXSTUVWXSTUVWXSTUY BCDEFABCDEFABCDEFABCDEFABCI MNOPQRMNOPORMINOPORMNOPORMNOI STUVWXSTUVWXXSTUVWXSTUVWXSTUY ABCDEFABCDEFABCDEFABCDEFABCI GHIJKLGHIJKLGHIJKLGHIJKLGHIC

Fig. 2 Images used for our analysis based on real animals. First row: surface visualizations of three-dimensional scanned carapaces. Second row: two-dimensional orthogonal projections of carapaces with eight landmarks in homologous positions (yellow dots). Third row: two-dimensional carapace silhouettes with Thompson-like grids.

cardiac region, the connection between carapace and pleon, and the outer margin of the eye cavities (Fig. 2, row 2). Following Bookstein's (1991) classification, the landmarks of the cardiac region, of the connection between carapace and pleon, and of the eyes are type I, because they mark corresponding structurally defined characteristics. By contrast, the landmarks marking the mirror axis (and the anterior-posterior ends) are type II or III [semi-landmarks after Bookstein
Fourth row: a Geryon carapace with an artificial grid that is used for the visualization of transformations applied to Geryon. b Image consisting of multiple alphabets used for the visualization of B-Splinebased transformations

(1997)]. Due to its convergent crab shape, the landmarks on the lithodid Paralomis might not exactly mark homologous structures, but in the case of the cardiac region homology is likely. Additionally, we generated artificial Thompson-like grids (Fig. 2, row 3) to mimic Thompson's approach in the following way: we extracted the outer borders of Thompson's grids and scaled them according to our silhouette images. Scaling was sufficient for all carapaces except for 
(a), which is not as wide as Thompson's equivalent and thus required additional movement of the left and right borders. The generation of the inner grid parts was straightforward except for (c), (d), and (f). Here, Thompson tried to create conformal grids. We used the Schwarz-Christoffel Toolbox for Matlab (Driscoll 1996) to create such conformal grids. Again, we sampled the grids with landmarks. Finally, we computed the transformations of our digitized real animals based on the black-and-white silhouettes, homologous landmarks, and the artificial Thompson-like grids.

Transformations based on landmarks were computed by applying Bookstein's thin-plate splines (Bookstein 1989). This method was used for transformations based on grids (using the landmark-sampled grids; applied to Thompson's original grids and our newly generated grids) and for the eight manually placed landmarks. Transformations based on superimposing the black-and-white silhouettes were computed using parametric image registration. We used B-Spline transformations as parametrization, the Kappa similarity metric combined with distances between additional landmarks as metric, and stochastic gradient descent as optimizer. In this way, we can create optimal solutions that either handle almost all shape details (using a fine B-Spline grid) or lead to simpler regular grids (using a coarse B-Spline grid). The Kappa similarity metric measures the overlap of the black carapace areas. Since when only considering the silhouette overlap, we observed too much freedom in the choice of the transformation, we included additional manually placed landmarks to guide the registration process. In case of the digitized real animals, we simply used the already existing eight homologous landmarks. In case of Thompson's drawings, we created eight landmarks on the border of the silhouette (Fig. 1, row 3). All computations were carried out with the registration software Elastix (Klein et al. 2010).

\section{Results}

\section{Testing Thompson's grid transformations}

As a first step, Thompson's own transformations of his illustrations were tested. Thompson (1917) used the carapace of Geryon (a) as reference shape for all grid-based transformations. By contrast, we computed the grid-based transformations between (a), (b), and (c), and between (d), (e), and (f), respectively, because the Thompson grids of (a), (b), and (c) have five horizontal lines, while (d), (e), and (f) only have four (Fig. 1). Furthermore, as opposed to Thompson, we performed the transformations in both directions, e.g., from ( $a$ to $b$ ) and from (b to a) (Fig. 3). Depending on the individual images, this test shows different degrees of similarity between the transformed shapes and the targets. The transformation from (a to $b$ ) and vice versa is quite accurate; in all other cases, the carapace transformations do not correspond to Thompson's carapace drawings (see second columns). The largest deviations appear in the transformations including the triangular carapaces of the spider crab (Majoidea) species Rochinia (c) and Chorinus (f) because of differences in the anterior region. Interestingly, the degree of some of the observed aberrations appears to be different with respect to the direction of transformation. Again, this relates to the spider crab shapes. This is, for instance, the case when (a to c) is compared with (c to a). Transformation of (a to c) results in a narrow, more or less rectangular shape, whereas the target shape is distinctly triangular tapering toward the anterior. By contrast, the grid transformation in the opposite direction (c to a) leads to an oval shape that surprisingly appears quite congruent to the target. This might be a mere psychological effect, because the areas that do not overlap are horizontally stretched.

\section{The transformation of Thompson's carapace drawings based on silhouettes}

In a second step, we transformed the carapace shapes of Thompson's drawings to test, how the grids are affected (Fig. 3). In this case, it was possible to use Geryon, shape (a), as reference for all other carapace shapes (Figs. 4, 5). To create optimal transformations of shape, we used B-Splines in two different ways: first, we used a very fine grid spacing of 32 pixels which leads to an almost perfect overlapping of the silhouettes but also strongly distorted and complex grids (4). These grids are greatly divergent from those of Thompson (compare Figs. 1 and 4). This is even the case in the seemingly simple transformation of (a to b) (Fig. 4). Assuming that Thompson tried to find simple global transformations, we applied a second B-Spline parameterization with a coarse grid spacing of 320 pixels. This led to simple and more regular grids while maintaining a relatively good shape congruence (Fig. 5). Nevertheless, as in the grid-based transformations (Fig. 3), the degrees of similarity between our results and those of Thompson differ depending on the individual transformations. The ( $a$ to $b$ ) and (a to d) grids are similar to those of Thompson. By contrast, the curvatures of Thompson's (1917) grid curves for (a to c), (a to e), and (a to f) seem to be arbitrary (Fig. 5, row 4). For instance, the grid lines of the transformation (a) to (e) converge, whereas those of Thompson (1917) diverge. Likewise, the strongly diverging lines of Thompson's (a to f) transformation could not be obtained with our approach.

\section{Applying transformations to real crabs}

The large aberrations revealed by our test of Thompson's figures led to the question whether this inaccuracy is an effect 
$a$ to $b$
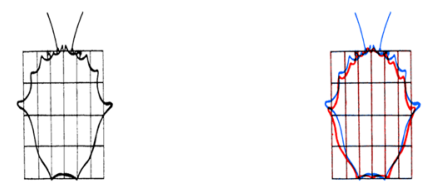

a to $c$
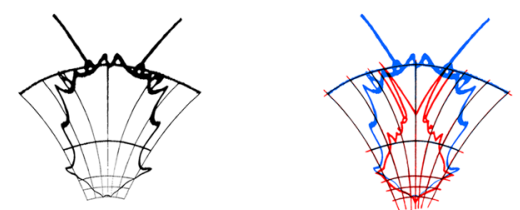

b to $\mathrm{c}$

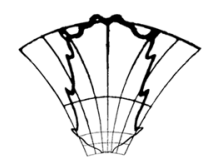

d to e
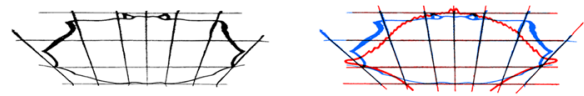

d to $f$

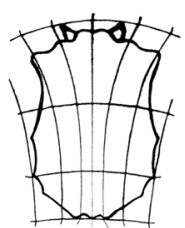

e to $f$
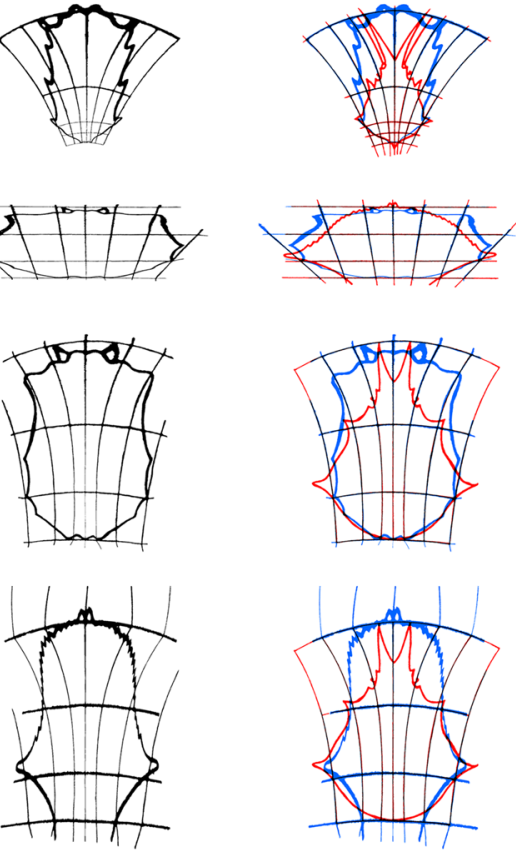

$\mathrm{b}$ to $\mathrm{a}$
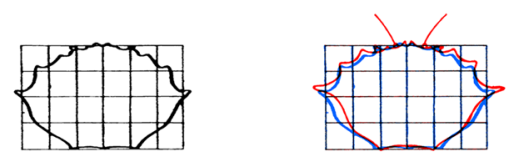

c to a
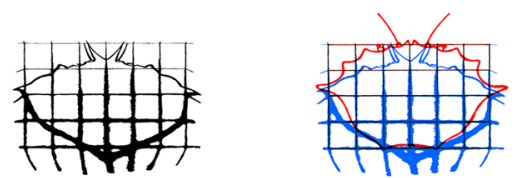

$c$ to $b$

e to $d$
Fig. 3 Original images of Thompson (1917) transformed with Thompson's grids using Bookstein warping. The Bookstein warping uses landmarks regularly distributed along the original grid lines (Fig. 1, row 2). The first three rows show all transformations between (a), (b), and (c). The final three rows show all transformations between $(\mathbf{d}),(\mathbf{e})$, and (f). It is not possible to compute any other trans-

of his relatively simple drawings or whether his method is inappropriate to grasp form shape changes of crab carapaces. To address this, we applied corresponding tests on digitized real crab carapaces.

The transformations of the digitized real animals using the Bookstein-warping grid-based transformations led to similar results as our grid transformations based on Thompson's drawings (Fig. 6). This similarity relates to the degrees of congruence and even the specific patterns of overlap (compare Fig. 6 with Fig. 3).

As is true for Thompson's sketches, the very fine B-Spline grid spacing of 32 pixels of the real carapaces led to transformed silhouettes that are greatly congruent with the targets, but the grids show dramatic distortions including intersecting lines as in (a to c) (Fig. 7). This situation is formation [e.g., between (a) and (d)], because the Thompson grids of $(\mathbf{a}-\mathbf{c})$ have five horizontal lines, while $(\mathbf{d}-\mathbf{f})$ only have four. The respective first columns only show transformed shapes and grids. The second columns show the transformed shapes in blue and the target shapes in red

much more relaxed in the 320-pixel spacing. Yet, the carapace shapes are more irregularly formed (Fig. 8). This concerns, in particular, the spines at the margins of the silhouettes (Fig. 8). Moreover, the resulting grids still differ to a large degree from those of Thompson's drawings. The best approximations are reached in (a to b) and (a to d).

\section{Landmark-based transformation of real crabs}

Thompson did neither explain whether nor how he used landmarks on the animal shapes for the construction of his crab carapace grids and their subsequent transformations. If, indeed, morphological structures were integrated wholes with strong correlations between most of their parts, transformations of a set of relatively few landmarks 

$a$ to $b$
a to $\mathrm{c}$
a to d
a to e
a to $f$
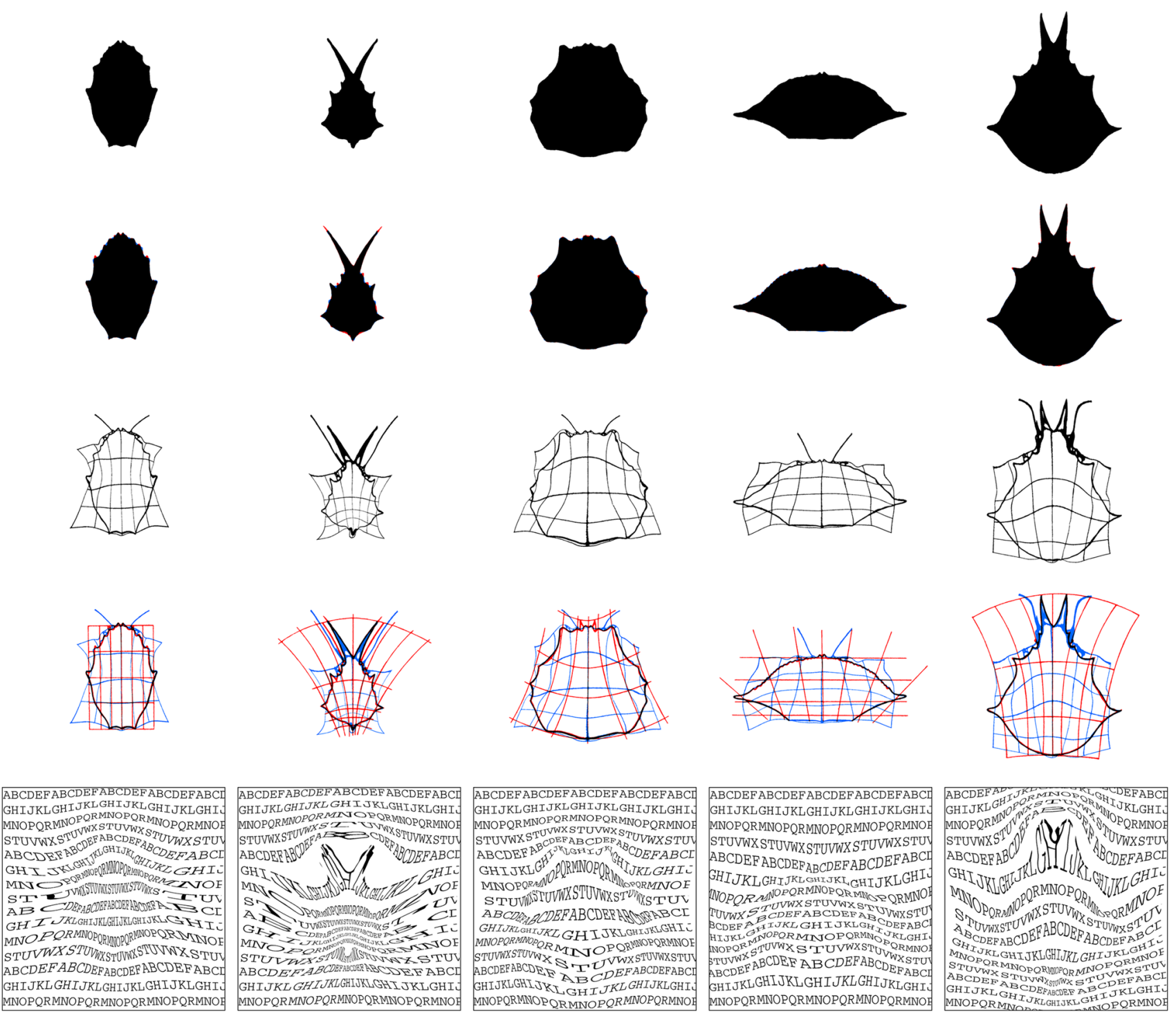

Fig. 4 Original images of Thompson transformed with B-Spline transformations using a grid spacing of 32 pixels. First row: transformed silhouettes. Second row: areas only belonging to the transformed silhouettes in blue, only belonging to the target silhouettes in red, and belonging to both in black. Third row: transformed shapes

in putatively homologous positions should result in congruence between the transformed reference shape (a) and the targets. The results can be found in Fig. 9, second row. In addition, the original grid was also transformed with respect to the same landmarks. The results are shown in Fig. 9, third row. This analysis reveals in some cases (a to $\mathrm{b}$, a to e) a reasonable in others a poor (a to c, a to f) overlap of carapace shapes. As in all experiments of our study, the two majoid species (c) and (f) cause the biggest problems. with grids. Fourth row: pixels only belonging to the transformed shapes in blue, only belonging to the target shapes in red, and belonging to both in black. Fifth row: transformation applied to alphabet image

\section{Discussion}

\section{Computation of transformations}

Thompson strove for simple transformations that would allow him to transform the silhouettes of the crab carapaces into one another. Guided by this motivation, we looked for a mathematical method that would also create simple transformations while, at the same time, require 

$a$ to $b$
a to $\mathrm{c}$
a to d
a to e
a to $f$
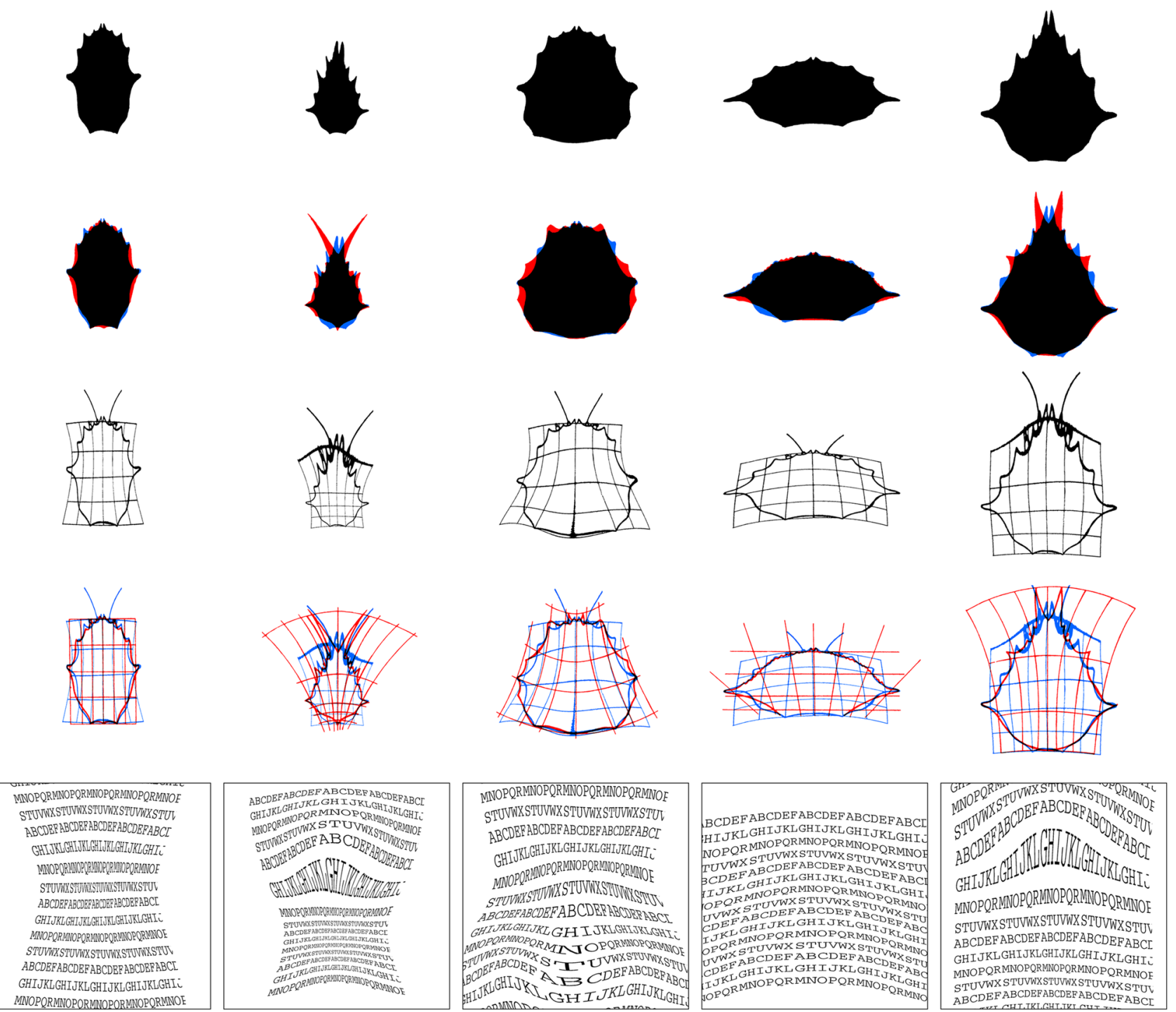

Fig. 5 Original images of Thompson transformed with B-Spline transformations using a grid spacing of 320 pixels. First row: transformed silhouettes. Second row: areas only belonging to the transformed silhouettes in blue, only belonging to the target silhouettes in red, and belonging to both in black. Third row: transformed shapes

little or no user input. B-spline transformations (Rueckert et al. 1999) represent such a method that has the advantage that one can easily adjust the degree of detail by changing the resolution of the grid of control points. Very fine grid resolutions often lead to transformations with the almost perfect match of the transformed silhouettes with the trade-off that the resulting transformations are often complex. Coarser grid resolutions, on the other hand, lead to simpler transformations while trading the accuracy of the matching. Hence, B-spline transformations seem to be with grids. Fourth row: pixels only belonging to the transformed shapes in blue, only belonging to the target shapes in red, and belonging to both in black. Fifth row: transformation applied to alphabet image

a good choice, because they allow the adjustment of the degree of simplicity.

Additionally, they can be combined with expert input in the form of landmarks as additional constraints. Hence, the landmark-guided approach also seems to be well justified. Ignoring this additional information often leaves too much freedom in the search for transformations. With the additional cues provided by the landmarks, however, we obtain both meaningful and simple transformations, where the degree of simplicity can be guided by a single parameter. 
$a$ to $b$
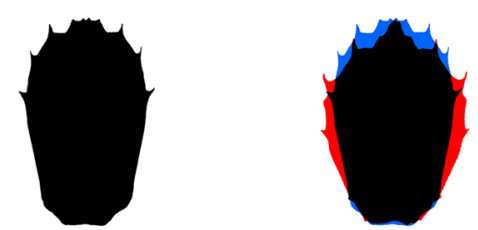

a to $\mathrm{c}$

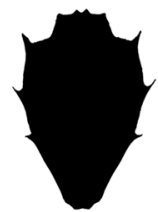

b to $\mathrm{c}$

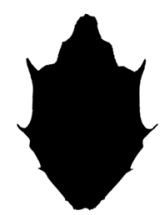

d to e

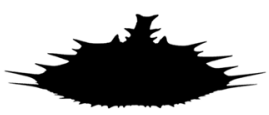

$d$ to $f$

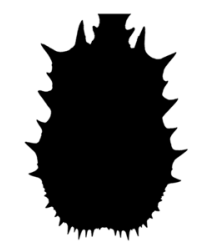

e to $f$
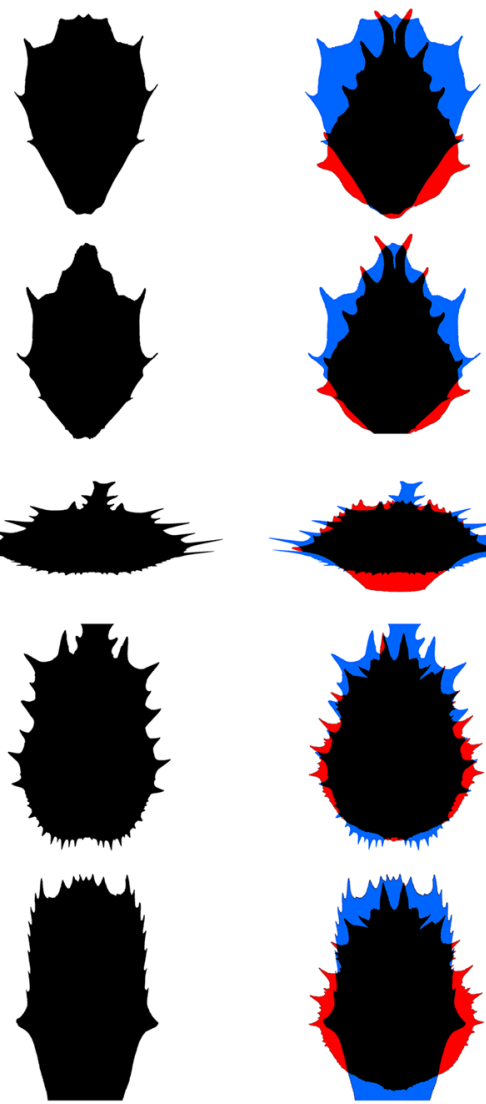

b to a

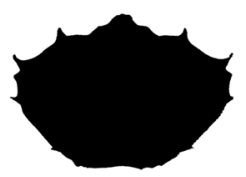

c to b
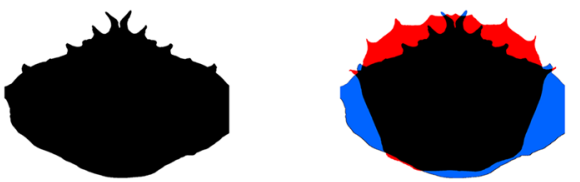

c to a
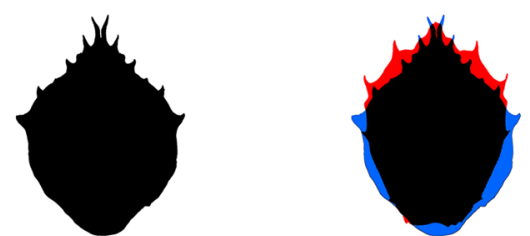

e to d

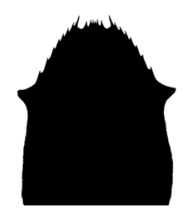

$f$ to $d$
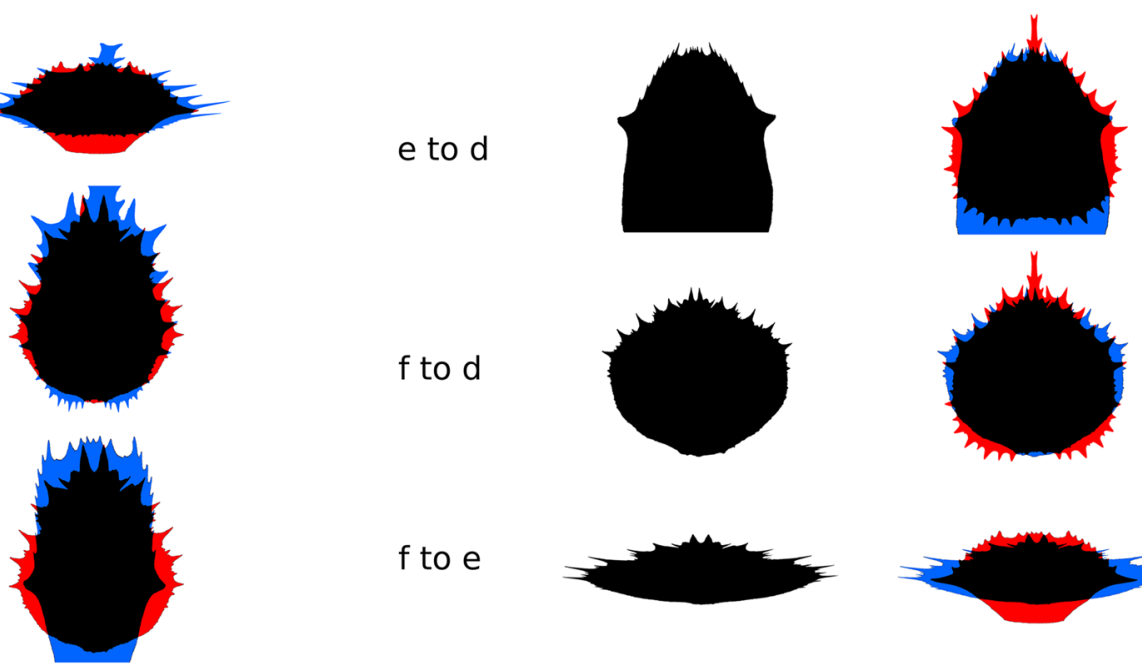

$f$ to $e$
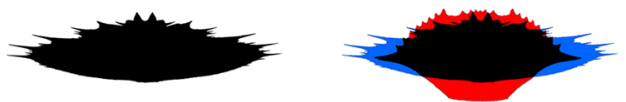

Fig. 6 Digitized real carapaces transformed with artificial Thompsonlike grids using Bookstein warping. The Bookstein warping uses landmarks regularly distributed along the artificial grid lines (Fig. 2, row 3). The respective first columns only show the transformed sil-

Of course, the transformations that we computed might not be the only meaningful and simple transformation that allows a good matching of the carapace silhouettes used by Thompson. However, our results clearly show that other simple transformations exist that lead to an even better matching of the silhouettes than by applying Thompson's transformations.

The computation of simple transformations leading to good correspondences with little distortions is still an active research topic. In this respect, the computation of conformal transformations is of interest, in particular, since Thompson also used them. One problem with conformal transformation is, however, that their exact computation is often not possible (see Segall and Ben-Chen 2016). Moreover, computation of conformal transformations also needs additional guidance concerning the boundary correspondence. In this article, we houettes. The second columns show areas only belonging to the transformed silhouettes in blue, only belonging to the target silhouettes in red, and belonging to both in black

followed the B-spline approach, because it is simpler and more easily accessible. Nevertheless, conformal transformations represent another promising approach that would be interesting to look into in the future.

\section{Thompson's Cartesian transformations}

Most of the original images transformed by us do not match the versions presented by Thompson (1917; see Fig. 3). It is obvious that only the simple transformation of lateral compression shows a satisfactory result (Geryon to Corystes, Fig. 3, a to b). The more complex the grid transformation, the less reliable is the match of the resulting images. The transformation of the grid of Geryon (a) to that of Rochinia (c) does not lead to a spider crab (Majoidea) as is depicted in Thompson's illustration and this is true for other examples, 
$a$ to $b$
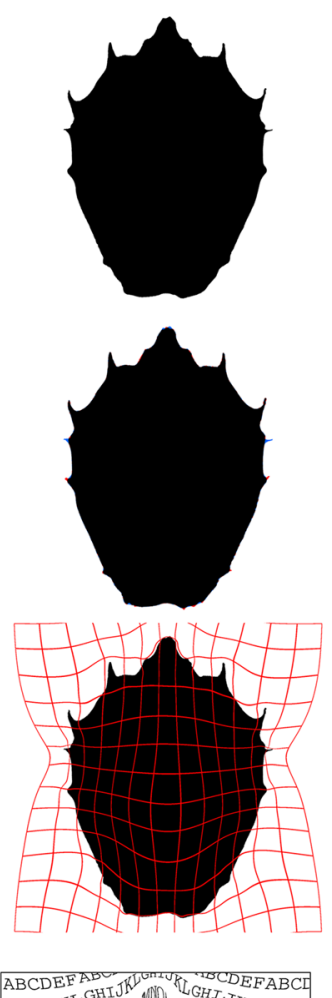
GHIJKI GHIJ 1 O DHI JKLGHI MNOPQ R MTUWXSTUWWST QRMNOF STUVWW' STUWWXSTUVWXST WV VWX STUT GHTJKLGHIJKLGHIJKLGHIJKLGBCL-

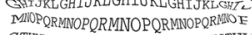
STUVWX STUVWX STUVWXSTUUWXSTUV ABCDEPABCDEFABCDEFABCDEFABCL GHIJKLGHI R ABC TR GHIJ RLGHII STUVWX OP GHI R NO WXSTUV

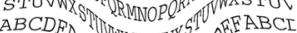
GHI EA A WW XTUVWX' CDE MNOPOD GL CDEFABCDEFA I JRI,GHI a to $\mathrm{c}$
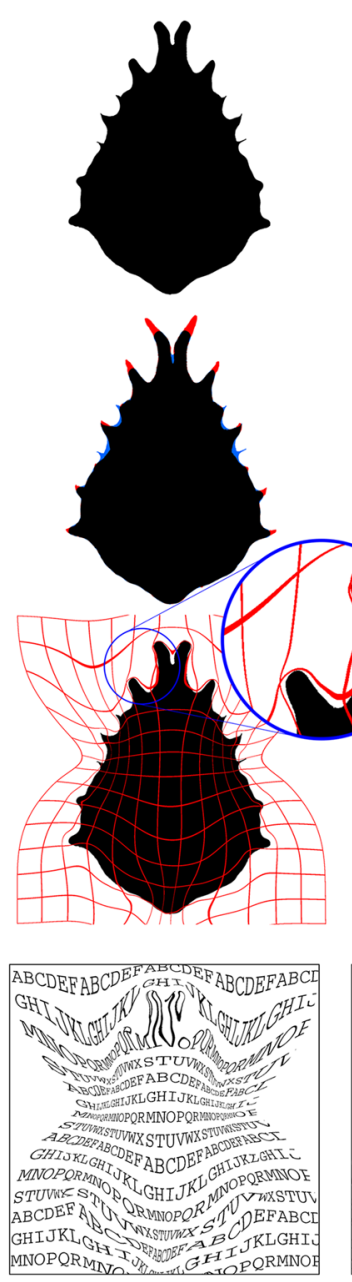

a to $d$
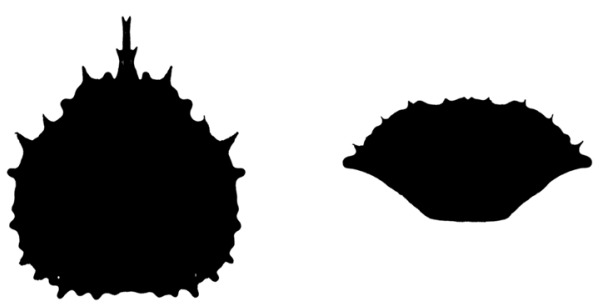

a to e

a to $f$
Fig. 7 Digitized real carapaces transformed with B-Spline transformations using a grid spacing of 32 pixels. First row: transformed silhouettes. Second row: areas only belonging to the transformed silhouettes in blue, only belonging to the target silhouettes in red, and belonging to both in black. Third row: transformed silhouettes with grids. The close-up for (a) to (c) shows strongly distorted, intersecting grid lines. Fifth row: transformation applied to alphabet image as well (Fig. 3). Methodically, these mismatches might be partly due to the inconsistent use of the grid by Thompson and the apparent absence of defined landmarks. For instance, it is not clear whether the anteriormost horizontal line marks the anterior tip of the animal or the anterior end of the eyes. Likewise, the number of horizontal lines varies between 4 and 5 with unclear correspondence in the posterior region and the (e) carapace is depicted without the posterior end.

Thompson (1917: 724) described his approach as if he had inscribed the outline of an organism (shape) in a system of Cartesian co-ordinates, which in a second step, it was transformed into a new shape based on changes in the grid co-ordinates (see above). By contrast, however, based on our results, we hypothesize that Thompson had drawn silhouettes copied from the animals and only secondarily superimposed the grid patterns that superficially would fit the proposed transformation. This would also explain the discrepancies noticed by Bookstein (1977: 181) in the transformation of the porcupine-fish to the sunfish as mentioned above. However, the relatively good match of the lateral compression of the grid of (a) and the resulting carapace with that of (b) might be caused by a different approach. Here, the result of the grid compression looks similar to the carapace of the digging crab species Corystes, and thus, it was called that way. A comparison with a real Corystes carapace, however, reveals quite a different shape (see Fig. 2b).

The B-Spline method shows that, in most cases, the grids used by Thompson are too simple. Not surprisingly, a fine spacing with an almost perfect congruence of carapace shapes demonstrates many deviations from Thompson's 
$a$ to $b$
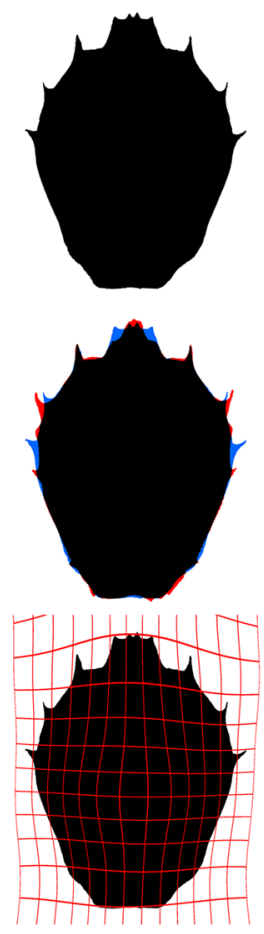

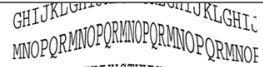
STUWWXSTUVWXSTUVWXSTUVWXSTUK ABCDEF ABCDEFABCDEP ABCDEFABCI GHIJKLGHIJKLGHIJKLGHIJKLGHIV MNOPORINOPQRMNOPQRMNOPQRMNOE STUWWXSTUVWXS TUUVWXSTUVWXSTUV
ABCDEFABCDEFABCDEFABCDEFABCI ABCDEFABCDEF ABCDEFABCDEFABCL MINOPQRMNOPQRMNOPORMNIOPQPMNIOF STUVWXSTUVW STUTWYSTTWXSTUT ABCDEPABCDEFABCDEFABCDEFABCI a to $\mathrm{c}$
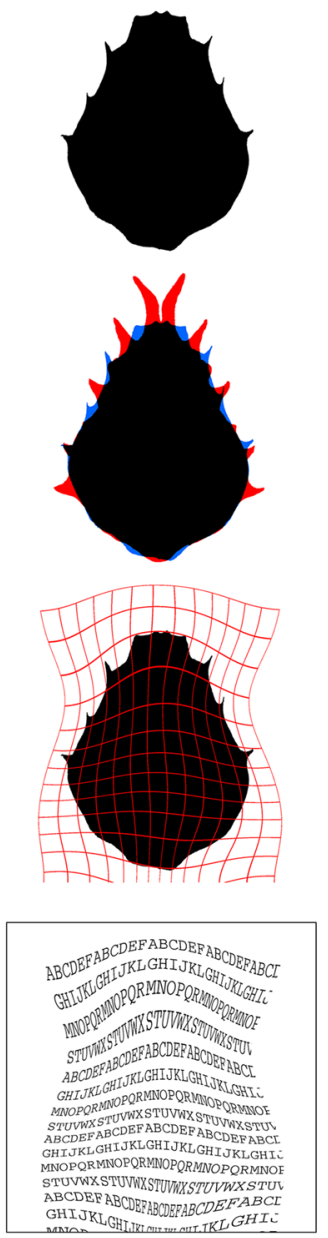

a to d
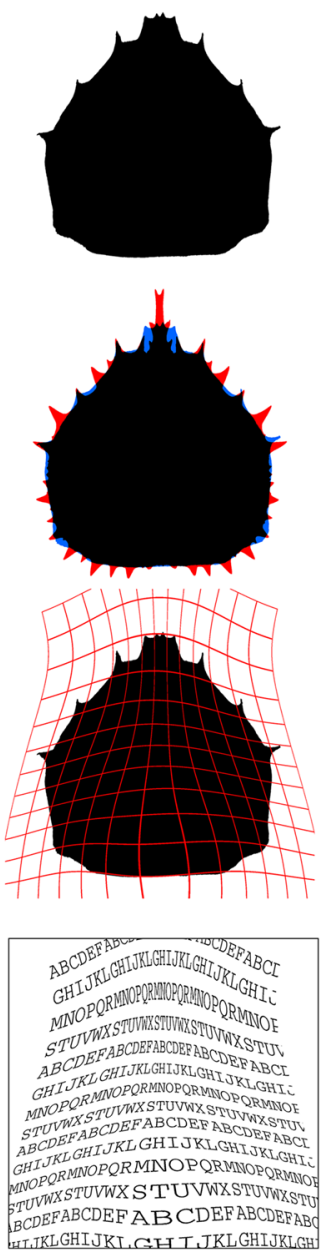

a to e

a to $f$
Fig. 8 Digitized real carapaces transformed with B-Spline transformations using a grid spacing of 320 pixels. First row: transformed silhouettes. Second row: areas only belonging to the transformed sil- houettes in blue, only belonging to the target silhouettes in red, and belonging to both in black. Third row: transformed silhouettes with grids. Fifth row: transformation applied to alphabet image original grids. The notable exceptions are Paralomis (d) which shows a similar converging line pattern. The more relaxed approach with a coarser spacing improves the situation with the compromise of a greater difference between transformed shapes and their targets.

Given the observed differences and difficulties, the question arises whether Thompson's method was really developed to describe the shape or "Gestalt" in every detail or just the underlying structure. He never explicitly mentioned this in the text, but from the treatment of the problem, one can deduce that he aimed to describe proper changes of shape and not just of underlying structures. He wrote, "...the chief, and indeed the essential, condition is, that the form of the entire structure under investigation should be found to vary in a more or less uniform manner, ..." (Thompson 1917: 726). In particular, this is the case in the example of the crab carapaces: "In a little more detail we may compare the outline of the carapace in various crabs one with another: and the comparison will be found easy and significant, even, in many cases, down to minute details, such as the number and situation of the marginal spines, though these are in other cases subject to independent variability." (Thompson 1917: 744).

It is obvious that the mathematical description or even quantification of complex shape changes requires a more complicated approach as has already previously been shown (e.g., Sokal and Sneath 1963; Bookstein 1977; MacLeod 2008) and, perhaps, it is an impossible task altogether. In any case, despite his recognition of the occasional occurrence of "independent variations" and "localised centres of diminished or exaggerated growth" (Thompson 1917: 726) which lead to deviations from a 
$a$ to $b$
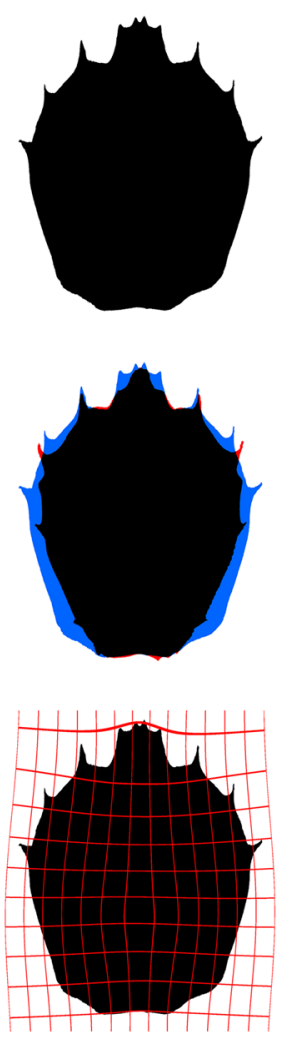

a to $\mathrm{c}$
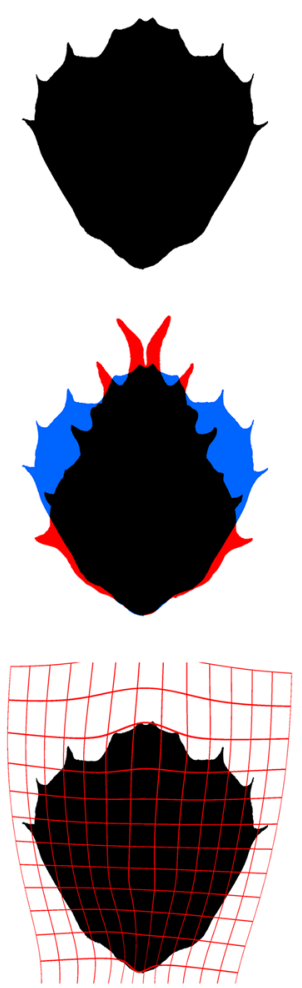

a to d
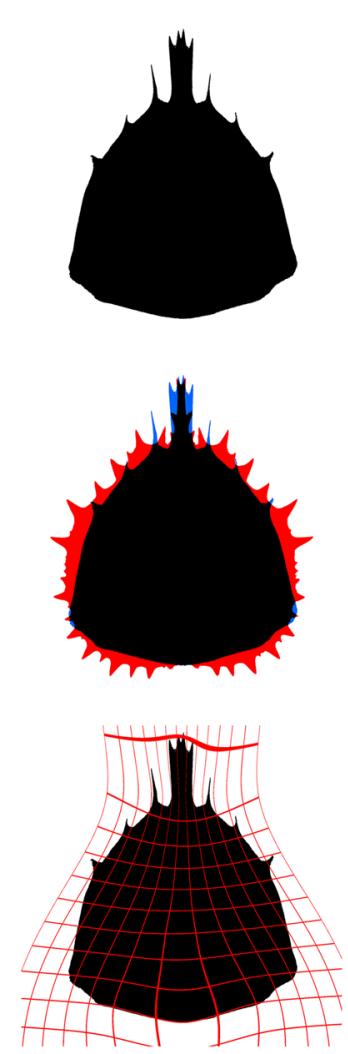

a to e

a to $f$
Fig. 9 Digitized real carapaces transformed with projected homologous landmarks using Bookstein warping. First row: transformed silhouettes. Second row: areas only belonging to the transformed sil- houettes in blue, only belonging to the target silhouettes in red, and belonging to both in black. Third row: transformed silhouettes with grids simple transformation, it is obvious that Thompson simplified the matter.

\section{Transformations of digitized carapaces of real animals}

The analyses using digitized real crab carapaces show largely corresponding results to those of Thompson's drawings. Using Thompson's grid patterns and transforming these to each other does not result in a reasonable shape congruence between most of the transformed silhouettes and the targets. As with Thompson's drawings, the generation of the shapes of the majoid representatives is most problematic (Fig. 6). The triangular form is never achieved. This reveals that the diverging lines used by Thompson to characterize the structure of the majoid carapaces are inappropriate to represent the transformation of trapezoid (Geryon), vertically oval (Corystes), and transversally oval (Portunus) carapaces to the triangular carapaces of majoids (Rochinia/Pisa and Chorinus/Leptomithrax). By contrast, the likewise triangular shape of lithodids is much better represented by the converging lines used by
Thompson as is shown by the transformation of the grid of Portunus to that of Paralomis/Lithodes. Surprisingly, the inverted transformations from the majoid grids to those of Geryon, Corystes, and Portunus lead seemingly to a much better congruence between transformed and target silhouettes. Again, this is the case for Thomson's drawings and the digitized carapaces. The reason for this might be a matter of perception. The size of the areas that do not overlap is the same in both directions of transformation. However, the different contours and positions lead to different impressions of shape similarity.

The fine B-spline grid spacing leads to complex grids, which differ even more from Thompson's originals. In the case of the majoids Pisa and Leptomithrax and the lithodid Lithodes, this approach leads to crossing lines and is beyond a simple Cartesian grid transformation. This changes with the coarse, more relaxed B-Spline transformation. As with the drawings of Thompson, the match between the silhouettes is worse and the grids get more regular. Yet only those of Corystes and Lithodes resemble Thompson's original grids. The others differ to various degrees. Portunus does not show diverging straight lines but an almost rectangular 
arrangement and the two majoid species reveal grids of an hourglass shape.

If a structural integration of shape transformation is assumed, a relatively low number of landmarks as basis for the calculation of transformation of one carapace shape into another should lead to satisfying results. As in all other approaches, the majoid shapes cause the biggest problems. Again, it is not possible to arrive at their triangular shape. Apparently, the majoid shape requires more landmarks than used by us. By contrast, as in the other experiments, the silhouette of the lithodid is satisfactorily achieved. Although it is also triangular. The resulting grids are all more or less showing a rectangular structure with the notable exception of that of Lithodes, which reveals the characteristic converging lines as in Thompson's original.

In summary, all approaches tested by us have to optimize between the exact shape and a simple geometric transformation. The better the transformed shape matches the target, the more complex the grid transformation becomes. In extreme cases, the grid is even dissolved and vortices are created. On the other hand, if the transformation of the grid is kept simple, the degree of congruence between the transformed morphological shape and the target is low. This could indicate that the interdependency between parts of an evolutionarily altered morphological structure is either very complex or that there is no interdependency, and the parts are individually and independently transformed in the course of evolution.

\section{Transformation and evolution}

In Thompson's transformation series (and consequently in ours), five of the six carapaces are from brachyuran crabs, in particular of the three eubrachyuran groups Majoidea, Portunoidea, and Corystidae (Table 1). The sixth carapace is not from a brachyuran. It stems from a species of the Lithodoidea, a group that is nested within hermit crabs (Paguroidea), but gave up the habit of living in gastropod shells (see Richter and Scholtz 1994; Reimann et al. 2011; Keiler et al. 2017; Noever and Glenner 2018) (Table 1). In the course of evolution, this led to a triangular appearance of the carapace, which closely resembles that of majoid brachyuran crabs (Scholtz 2014). Paguroids including lithodids belong to a large and very diverse decapod group called Anomala or Anomura (e.g., Reimann et al. 2011; Tan et al. 2018), which is most likely the sister group to Brachyura (e.g., Scholtz and Richter, 1995; Shen et al. 2013: Wolfe et al. 2019). Hence, this species is only distantly related to the brachyurans and the triangular carapace is the result of convergent evolution (Scholtz 2014; Keiler et al. 2017). There is no indication that Thompson was aware of the fact that one of the carapaces does not belong to a brachyuran (see Scholtz 2014).
As shown above, the shape of Majoidea is too different from that of other brachyuran crabs to be represented by a simple transformation. By contrast, the far more distantly related non-brachyuran crab Lithodes maja shows acceptable results concerning the transformation methods carried out by us. Hence, our transformation experiments show that the form change between closely related brachyurans is more complex than between some brachyurans and distantly related anomalan species that underwent convergent evolution towards a brachyuran carapace shape. This example shows that Thompson's approach to transformations has no reliable predictive power. Paguroid hermit crabs are by no means intermediate forms between brachyuran crabs with trapezoid carapaces and lithodids.

Hence, these findings are not only problematic with respect to current views about decapod phylogeny, they also contradict Thompson's own views about continuity of form within a given group and discontinuity including larger gaps between them (Thompson 1917, 1942).

Nevertheless, despite the problematic aspects of Thompson's approach, there are cases in which evolutionary transformations can be described by relatively simple grid transformations. However, the crucial question is how this phenomenon can be explained. As Breidbach (2008: 18) stated, Thompson "did not achieve an analytical framework underlying the pictures he used." Hence, one can think of several interpretations of Thompson's examples. Are Thompson's transformations nothing but a special case of a (functional) correlation of two or more characters (Hennig 1950: 169)? Are they an indication of some sort of internal stabilizing mechanism such as a genetic or developmental character integration (Riedl 1975; Wagner 2014)? Are they just a trivial result of form change, in which inherited characters are used and altered without any integration mechanism just, because they are there, in other words, the evolutionary principle of the "use of existing structures" (Scholtz 2017)? These questions lie at the heart of morphology as a discipline (Gould and Lewontin 1979; Scholtz 2010; Richter and Wirkner 2013; Wanninger 2015) and there is no definitive answer yet.

\section{Scientific icons}

A number of scientific images have gained iconic status. These icons of science are characterized by the circulation of numerous copies and modifications and show a great impact on science and culture (Hopwood 2015). Wellknown examples for this are the evolutionary branching diagram published by Darwin (1859), the cartoon of the "raise of man" by Huxley (1863), the table of comparative evolutionary embryology by Haeckel (1872), and the image of the DNA double helix by Watson and Crick (1953) (for comprehensive accounts of this topic, see 
Gould 1989; Bredekamp 2005; Hopwood 2015). Many of the images of Thompson's book (1917), in particular those on the theory of transformation, fall into the same category, i.e., they became icons of science with an enormous impact even far beyond science.

Interestingly, despite their great impact, some of these iconic images are based on erroneous assumptions, wrong concepts, great simplifications, and different degrees of manipulation. Darwin's evolutionary "tree" is probably based on an alga that he collected during his cruise with the Beagle and which he mistook for a coral (Bredekamp 2005). Huxley's arrangement of apes and human in row has been criticized for exemplifying the rather ancient, pre-evolutionary idea of the great chain of being (see Lovejoy 1936) instead of that of evolution, which has to be represented by a branching diagram (Gould 1989). The most notorious example, however, is the embryonic table of Haeckel, for which Haeckel has been accused of manipulation of details and even fraud to make the pictures fit his evolutionary ideas (see Hopwood 2015).

Our data show a distinct misfit between Thompson's claims concerning Cartesian transformation and what actually happens to the images when Thompson's method is used. It is not clear whether these discrepancies are based on intention, i.e., that Thompson manipulated the data to some degree to gain a better fit to his ideas. Yet, it must be stressed that we tested only one of several figures and the other examples used by Thompson have to be analyzed with the same scrutiny before a general conclusion can be drawn. Nevertheless, Bookstein's (1977) critique of Thompson's moonfish image and the video loop on human to chimpanzee skull transformation of O'Neill (2009) strongly suggest that more of Thompson's images are problematic.

Acknowledgements Open Access funding provided by Projekt DEAL. We thank Stefan Zachow and Carola Becker for valuable discussions and Till Ramm for help with the scanning of crab carapaces. Funding was received by the Cluster of Excellence "Image Knowledge Gestaltung"- an interdisciplinary laboratory, project "Dynamic Form" at the Humboldt-Universität zu Berlin. We are grateful to Thomas Stach and Stefan Richter for helpful comments on an earlier version of this manuscript.

Author contributions All authors have contributed to the study conception and design. Material preparation, data collection, and analysis were performed by DK, DB, and GS. All transformations and images were computed by DK. The first draft of the manuscript was written by GS and DK. All authors commented on the previous versions of the manuscript. All authors read and approved the final manuscript.

Funding This study was funded by the Cluster of Excellence "Image Knowledge Gestaltung"-an interdisciplinary laboratory, project "Dynamic Form" at the Humboldt-Universität zu Berlin.

\section{Compliance with ethical standards}

Conflict of interest All authors declare that they have no conflict of interest.

Ethical approval This article does not contain any studies with human participants or animals performed by any of the authors.

Open Access This article is licensed under a Creative Commons Attribution 4.0 International License, which permits use, sharing, adaptation, distribution and reproduction in any medium or format, as long as you give appropriate credit to the original author(s) and the source, provide a link to the Creative Commons licence, and indicate if changes were made. The images or other third party material in this article are included in the article's Creative Commons licence, unless indicated otherwise in a credit line to the material. If material is not included in the article's Creative Commons licence and your intended use is not permitted by statutory regulation or exceeds the permitted use, you will need to obtain permission directly from the copyright holder. To view a copy of this licence, visit http://creativecommons.org/licenses/by/4.0/.

\section{References}

Abzhanov A (2017) The old and new faces of morphology: the legacy of D'Arcy Thompson's 'theory of transformations' and 'laws of growth'. Development 144:4284-4297

Arthur W (2006) D'Arcy Thompson and the theory of transformations. Nat Rev Genet 7:401-406

Asma ST (1996) Following form and function. A philosophical archeology of life science. Northwestern University Press, Evanston

Ball P (2013) In retrospect: on growth and form. Nature 494:32-33

Beesley P, Bonnemaison S (eds) (2008) On growth and form: organic architecture and beyond. Tuns Press and Riverside Architectural Press, Toronto

Bookstein FL (1977) The study of shape transformation after D'Arcy Thompson. Math Biosci 34:177-219

Bookstein FL (1989) Principal warps: thin-plate splines and the decomposition of deformations. IEEE T Pattern Anal 11:567-585

Bookstein FL (1991) Morphometric tools for landmark data: geometry and biology. Cambridge University Press, Cambridge

Bookstein FL (1997) Landmark methods for forms without landmarks: morphometrics of group differences in outline shape. Med Image Anal 1:225-243

Bredekamp H (2005) Darwins Korallen. Frühe Evolutionsmodelle und die Tradition der Naturgeschichte. Wagenbach, Berlin

Breidbach O (2008) Concept of morphology-some historical remarks. In: Breidbach O, Corvaja P, Vianello A, Vercellone F (eds) Concept of morphology. Mimesis, Milan, pp 9-25

Darwin C (1859) On the origin of species by means of natural selection. John Murray, London

Doczi G (1981) The power of limits. Shambhala, Boulder

Driscoll TA (1996) Algorithm 756: a MATLAB toolbox for SchwarzChristoffel mapping. ACM T Math Software 22:168-186

Dunlop JWC, Weinkamer R, Fratzl P (2011) Artful interfaces within biological materials. Mater Today 14:70-78

Fratzl P, Weiner S (2010) Bio-inspired materials-mining the old literature for new ideas. Adv Mater 22:4547-4550

Fürst von Lieven A (2017) Der Körper als angewandte Mathematik. Nat wiss Rundsch 70:286-292

Gould SJ (1971) D'Arcy Thompson and the science of form. New Lit Hist 2:229-258 
Gould SJ (1989) Wonderful Life: the burgess shale and the nature of history. Norton, New York

Gould SJ, Lewontin RC (1979) The spandrels of San Marco and the Panglossian paradigm: a critique of the adaptionist programme. Proc R Soc Lond B 205:581-598

Haeckel E (1872) Natürliche Schöpfungsgeschichte, 3rd edn. Reimer, Berlin

Hennig W (1950) Grundzüge einer Theorie der Phylogenetischen Systematik. Deutscher Zentralverlag, Berlin

Hiller A, Kraus H, Almon M, Werding B (2006) The Petrolisthes galathinus complex: species boundaries based on color pattern, morphology and molecules, and evolutionary interrelationships between this complex and other Porcellanidae (Crustacea: Decapoda: Anomura). Mol Phylogenet Evol 40:547-569

Höfler C (2013) Doppelte Monster, infizierte Körper. William Bateson, D'Arcy Thompson und die computerbasierte Architektur. In: Bruhn M, Scholtz G (eds) Morphologien. Bildwelten des Wissens 9.2. Akademie Verlag, Berlin, pp 7-17

Hopwood N (2015) Haeckel's embryos. images, evolution, and fraud. Chicago University Press, Chicago

Huxley TH (1863) Evidence as to man's place in nature. Appleton \& Company, New York

Jarron M (2015) A sketch of the universe-the visual influences of D'Arcy Thompson's on growth and form. J Illustr 2:31-50

Keiler J, Wirkner CS, Richter S (2017) One hundred years of carcinization - the evolution of the crab-like habitus in Anomura (Arthropoda: Crustacea). Biol J Linnean Soc 121:200-222

Klein S, Staring M, Murphy K, Viergever MA, Pluim JP (2010) Elastix: a toolbox for intensity-based medical image registration. IEEE Trans Med Imaging 29:196-205

Knötel D, Becker C, Scholtz G, Baum D (2018) Global and Local Mesh Morphing for Complex Biological Objects from $\mu$ CT Data. In: Puig Puig A, Schultz T, Vilanova A (eds) Eurographics Workshop on Visual Computing for Biology and Medicine, pp 179-183

Lecuit T, Mahadevan L (2017) Editorial: Morphogenesis one century after On Growth and Form. Development 144:4197-4198

Lovejoy AO (1936) The great chain of being. A study of the history of an idea. Harvard University Press, Cambridge

Lynn G (2017) Embryological house. In: Doll N, Bredekamp H, Schäffner W (eds) +ultra. knowledge \& gestaltung. Seemann, Leipzig, p 153

MacLeod N (2008) Understanding morphology in systematic contexts. Three-dimensional specimen ordination and recognition. In: Wheeler QD (ed) The New Taxonomy. CRC Press, Boca Raton, pp 143-209

Mahner M, Bunge M (1997) Foundations of biophilosophy. Springer, Berlin

Marsland S, McLachlan RI, Modin K, Perlmutter M (2012) Geodesic warps by conformal mappings. arXiv: 1203.3982v2 (math.DS). Accessed 26 July 2012

McLaughlin PA (1980) Comparative morphology of recent Crustacea. Freeman and Company, San Francisco

Ng PKL, Guinot D, Davie PJF (2008) Systema Brachyurorum: Part I. an annotated checklist of extant Brachyuran crabs of the world. Raffles B Zool 17:1-286

Noever C, Glenner H (2018) The origin of king crabs: hermit crab ancestry under the magnifying glass. Zool J Linnean Soc 182:300-318

O’Neill R (2009) “Theory of Transformations" Loop: https://vimeo .com/8280375. Accessed 10th June 2020

Ospina-Garcés SM, Hernández-Cardenas JA, Toledo-Hernández VH, Corona-López AM, Flores-Palacios A (2018) Head shape variation in cerambycid saproxylic beetles as a function of host plant selection. Arthropod Struct Dev 47:2-11

Oxnard C, O'Higgins P (2009) Biology clearly needs morphometrics. Does morphometrics need biology? Biol Theory 4:84-97
Reimann A, Richter S, Scholtz G (2011) Phylogeny of the Anomala (Crustacea, Decapoda, Reptantia) based on the ossicles of the foregut. Zool Anz 250:316-342

Reindl A, Schubert T, Strobach T, Becker C, Scholtz G (2018) Adaptation aftereffects in the perception of crabs and lobsters as examples of complex natural objects. Front Psychol 9:1905

Richter S, Scholtz G (1994) Morphological evidence for a hermit crab ancestry of lithodids (Crustacea, Decapoda, Anomala, Paguroidea). Zool Anz 233:187-210

Richter S, Wirkner CS (2013) Objekte der Morphologie. In: Bruhn M, Scholtz G (eds) Morphologien. Bildwelten des Wissens 9.2. Akademie Verlag, Berlin, pp 83-96

Riedl R (1975) Die Ordnung des Lebendigen. Parey, Hamburg

Rueckert D, Sonoda LI, Hayes C, Hill DL, Leach MO, Hawkes DJ (1999) Nonrigid registration using free-form deformations: application to breast MR images. IEEE Trans Med Imaging 18:712-721

Ruse M (2013) From organicism to mechanism-and halfway back? In: Henning BG, Scarfe A (eds) Beyond mechanism: putting life back into biology. Lexington Books, London, pp 409-430

Sanfelice D, de Freitas TRO (2007) The ontogeny of shape disparity in three species of otariids (Pinnipedia: Mammalia). Lat Am J Aquat Res 6:139-154

Saunders TE, Ingham PW (2017) Editorial: MoD Special Issue celebrating 100 years since "On Growth and Form” by D'Arcy Wentworth Thompson. Mech Dev 145:1

Scholtz G (2010) Deconstructing morphology. Acta Zool 91:44-63

Scholtz G (2013) Versuch einer analytischen Morphologie. In: Bruhn M, Scholtz G (eds) Morphologien. Bildwelten des Wissens 9.2. Akademie Verlag, Berlin, pp 30-44

Scholtz G (2014) Evolution of crabs-history and deconstruction of a prime example of convergence. Contrib Zool 83:87-105

Scholtz G (2017) Evolution as designer? In: Doll N, Bredekamp H, Schäffner W (eds) +ultra. knowledge \& gestaltung. Seemann, Leipzig, pp 111-116

Scholtz G, Richter S (1995) Phylogenetic systematics of the reptantian Decapoda (Crustacea, Malacostraca). Zool J Linnean Soc 113:289-328

Segall A, Ben-Chen M (2016) Iterative closest conformal maps between planar domains. Comput Graph Forum 35:33-40

Shen H, Braband A, Scholtz G (2013) Mitogenomic analysis of decapod crustacean phylogeny corroborates traditional views on their relationships. Mol Phylogenet Evol 66:776-789

Sokal RR, Sneath PHA (1963) Principles of Numerical Taxonomy. Freeman, San Francisco

Tan MH, Gan HM, Leeb YP, Linton S, Grandjean F, Bartholomei-Santose ML, Miller AD, Austin CM (2018) Order within the chaos: Insights into phylogenetic relationships within the Anomura (Crustacea: Decapoda) from mitochondrial sequences and gene order rearrangements. Mol Phylogenet Evol 127:320-331

Thompson DAW (1915) Morphology and mathematics. Trans Roy Soc Edinburgh 50:857-895

Thompson DAW (1917) On growth and form. Cambridge University Press, Cambridge

Thompson DAW (1942) On growth and form, 2nd edn. Cambridge University Press, Cambridge

Wagner G (2014) Homology, genes, and evolutionary innovation. Princeton University Press, Princeton

Wanninger A (2015) Morphology is dead-long live morphology! Integrating MorphoEvoDevo into molecular EvoDevo and phylogenomics. Front Ecol Evol 3:54

Watson JD, Crick FHC (1953) Molecular structure for deoxyribonucleic acids. Nature 171:737

Werritty A (2010) D’Arcy Thompson's 'On Growth and Form' and the rediscovery of geometry within the geographic tradition. Scott Geogr J 126:231-257 
Wolfe JM, Breinholt JW, Crandall KA, Lemmon AR, Moriarty Lemmon E, Timm LE, Sidall ME, Bracken-Grissom HD (2019) A phylogenomic framework, evolutionary timeline and genomic resources for comparative studies of decapod crustaceans. Proc R Soc Lond B 286:20190079

Zelditch ML, Swiderski DL, Sheets HD, Fink WL (2004) Geometric morphometrics for biologists: a primer. Elsevier Academic Press, San Diego
Publisher's Note Springer Nature remains neutral with regard to jurisdictional claims in published maps and institutional affiliations. 